OPEN ACCESS

Edited and Reviewed by: Mehdi Mirsaeidi, University of Miami, United States

${ }^{*}$ Correspondence:

Argyrios Tzouvelekis argyrios.tzouvelekis@fleming.gr

tThese authors have contributed equally to this work.

¥These authors jointly supervised the work.

Specialty section: This article was submitted to Pulmonary Medicine, a section of the journal

Frontiers in Medicine

Received: 06 December 2017 Accepted: 22 December 2017

Published: 24 January 2018

Citation:

Tzouvelekis A, Karampitsakos T, Ntolios P, Tzilas V, Bouros E,

Markozannes E, Malliou I, Anagnostopoulos A, Granitsas A,

Steiropoulos P, Dimakou K,

Chrysikos S, Koulouris N and

Bouros D (2018) Corrigendum: Longitudinal "Real-World" Outcomes of Pirfenidone in Idiopathic Pulmonary Fibrosis in Greece. Front. Med. 4:257. doi: 10.3389/fmed.2017.00257

\section{Corrigendum: Longitudinal "Real-World" Outcomes of Pirfenidone in Idiopathic Pulmonary Fibrosis in Greece}

Argyrios Tzouvelekis ${ }^{1,2 * \neq}$, Theodoros Karampitsakos ${ }^{3 \dagger}$, Paschalis Ntolios ${ }^{4}$, Vasilios Tzilas ${ }^{1}$, Evangelos Bouros ${ }^{1}$, Evangelos Markozannes', Ioanna Malliou ${ }^{1}$, Aris Anagnostopoulos ${ }^{1}$, Andreas Granitsas ${ }^{1}$, Paschalis Steiropoulos ${ }^{2}, K_{\text {Katerina Dimakou }}^{3}$, Serafeim Chrysikos ${ }^{4}$, Nikolaos Koulouris ${ }^{1}$ and Demosthenes Bouros ${ }^{1 \neq}$

"First Academic Department of Pneumonology, Hospital for Diseases of the Chest "Sotiria", Medical School, National and Kapodistrian University of Athens, Athens, Greece, ${ }^{2}$ Division of Immunology, Biomedical Sciences Research Center "Alexander Fleming", Athens, Greece, ${ }^{3} 5$ th Respiratory Department, Hospital for Diseases of the Chest "Sotiria", Athens, Greece, ${ }^{4}$ Department of Pneumonology, University Hospital of Alexandroupolis, Democritus University of Thrace, Komotini, Greece

Keywords: pirfenidone, safety, efficacy, idiopathic pulmonary fibrosis, treatment

\section{A corrigendum on}

Longitudinal "Real-World" Outcomes of Pirfenidone in Idiopathic Pulmonary Fibrosis in Greece

by Tzouvelekis A, Karampitsakos T, Ntolios P, Tzilas V, Bouros E, Markozannes E, et al. Front Med (2017) 4:213. doi: 10.3389/fmed.2017.00213

In the original article, there was a mistake in Figure $\mathbf{1}$ as published $[x$ and $y$ axes were mislabeled and ${ }^{\star} p$-value $<0.05$ indicating significance was missing]. The corrected Figure 1 appears below. The authors apologize for this error and state that this does not change the scientific conclusions of the article in any way.

In the original article, there was a mistake in Figure 2 as published $[x$ and $y$ axes were mislabeled and ${ }^{\star} p$-value $<0.05$ indicating significance was missing]. The corrected Figure 2 appears below. The authors apologize for this error and state that this does not change the scientific conclusions of the article in any way.

The original article was updated. 


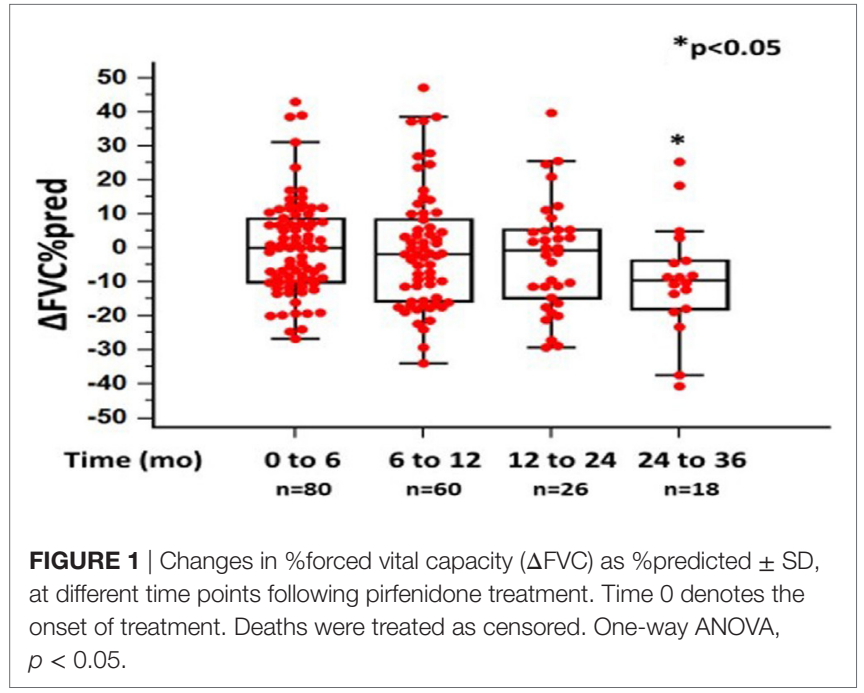

Conflict of Interest Statement: The authors declare that the research was conducted in the absence of any commercial or financial relationships that could be construed as a potential conflict of interest.

Copyright (C) 2018 Tzouvelekis, Karampitsakos, Ntolios, Tzilas, Bouros, Markozannes, Malliou, Anagnostopoulos, Granitsas, Steiropoulos, Dimakou, Chrysikos, Koulouris

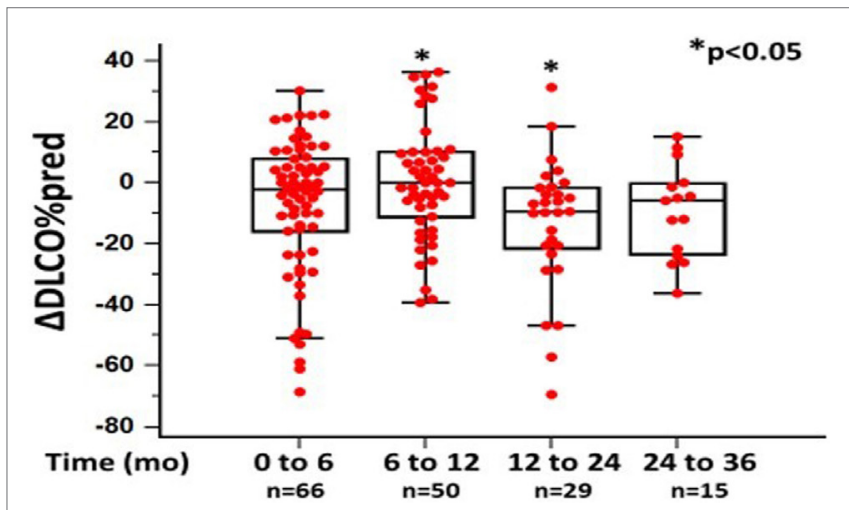

FIGURE 2 | Changes in \%diffusion capacity of lung for carbon monoxide $\left(\Delta \mathrm{D}_{\mathrm{co}}\right)$ as \%predicted $\pm \mathrm{SD}$, at different time points following pirfenidone treatment. Time 0 denotes the onset of treatment. Deaths were treated as censored. One-way ANOVA, $p<0.05$.

and Bouros. This is an open-access article distributed under the terms of the Creative Commons Attribution License (CC BY). The use, distribution or reproduction in other forums is permitted, provided the original author(s) or licensor are credited and that the original publication in this journal is cited, in accordance with accepted academic practice. No use, distribution or reproduction is permitted which does not comply with these terms. 